\title{
The cerebral vasculature in dementia pugilistica
}

\author{
C W M ADAMS, ${ }^{*} \dagger$ C J BRUTON* \\ From the Department of Neuropathology, Runwell Hospital,* Wickford, Essex, Division of Histopathology, \\ United Medical and Dental Schools of Guy's and St Thomas's Hospitals, $\dagger$ London University, and Division of \\ Psychiatry, Clinical Research Council, Northwick Park Hospital, $\ddagger$ Harrow, Middlesex
}

SUMMARY The brains of 22 ex-boxers were examined histologically to determine the frequency of recent or old haemorrhage. Four boxers had died from an acute intracerebral bleed, usually soon after a boxing bout. Seven of the other 18 showed evidence of previous perivascular haemorrhage, as detected by Perls' ferrocyanide test for iron, and a similar number showed minor degrees of meningeal or subpial siderosis, consistent with previous meningeal bleeding; cerebellar siderosis was present in six cases. Seventeen of the 22 boxers showed evidence of recent or past haemorrhage. Control material showed an incidence of $11 \%$ for perivascular iron deposition and only $4 \%$ for minor degrees of meningeal siderosis.

Brain damage caused during boxing has been reported by several authors (see refs 1, 2 for detailed references). Sudden fatal injuries are rare and usually due to haemorrhage, most frequently subdural and subarachnoid, whereas the neuropathology of the "punchdrunk" state (dementia pugilistica) involves a tetrad of apparently different pathological processes which affect parts of the brain stem, the cerebellum and the cerebral hemispheres, respectively. These processes include degeneration of the substantia nigra, cerebellar scarring, partial disintegration of the septum pellucidum and the widespread presence of Alzheimer's neurofibrillary tangles without neuritic plaques, particularly in the medial temporal cortex. Although the mechanisms of these latter injuries are poorly understood, Corsellis and colleagues ${ }^{1}$ did not consider that they were the direct result of vascular damage. Nevertheless, Martland ${ }^{3}$ who first introduced the concept of the "punch-drunk" state inferred that repeated blows to the head would produce multiple "concussion haemorrhages" of the type described by Cassasa ${ }^{4}$ in five patients who died following a massive single blow to the head.

More recently, however, the mechanisms of head injury have been further studied in experimental animals $^{56}$ and, although many of these have been "single-blow" experiments, experience has shown that the pattern of damage produced by linear (translational) acceleration differs from that produced when

Address for reprint requests: Professor C W M Adams, Department of Neuropathology, Runwell Hospital, Wickford, Essex SS11 7QE, UK.

Received 19 August 1988 and in revised form 17 December 1988. Accepted 19 December 1988 a rotational (angular) force is applied to the brain. (In boxing these forces are exemplified respectively by a straight blow to the head and an uppercut.) Ommaya and Gennarelli ${ }^{7}$ showed that linear or translational accelerations do not produce concussion, whereas rotational acceleration readily does so. At low and moderate acceleration levels rotational acceleration produces transient concussion with or without cerebral contusions ${ }^{8}$ but, at higher acceleration, animals die from acute subdural haemorrhage because of rupture of the parasagittal bridging veins.

No matter which force is applied, however, rupture of blood vessels appears to be an important factor in the pathogenesis of experimental head injury. Because of this, it seemed appropriate to reinvestigate the cerebral vasculature in a number of boxers' brains in order to assess how often the observations in experimental animals could be visualised in man.

\section{Materials and methods}

The brains of 22 boxers were studied from the neuropathology collection at Runwell Hospital. These included 13 of the original 15 cases reported by Corsellis, Bruton and FreemanBrowne'; ten of the 13 men had boxed professionally, although in one case the information was unreliable; two were at one time world champions and six more had won or fought for a national or regional championship. All but one of them (the ex-professional with the unreliable history) showed neuropathological evidence of brain damage of the type described in the "punch-drunk" state (table).

The brains of a further nine boxers were also examined; four of these boxers had become comatose within thirty minutes of a boxing bout and did not regain consciousness. At necropsy, their brains were found to have naked-eye evidence of recent subdural, subarachnoid or intracerebral 
Table Cerebrovascular lesions in 22 boxers

\begin{tabular}{|c|c|c|c|c|c|c|c|c|c|}
\hline Boxing status & No & $\begin{array}{l}\text { Mean age } \\
(y r, S D)\end{array}$ & $\begin{array}{l}\text { Dementia } \\
\text { pugilistica* }\end{array}$ & $\begin{array}{l}\text { No vascular } \\
\text { lesions }\end{array}$ & $\begin{array}{l}\text { Iron } \\
\text { around } \\
\text { cerebral } \\
\text { vessels }\end{array}$ & $\begin{array}{l}\text { Meningeal } \\
\text { or subpial } \\
\text { iron }\end{array}$ & $\begin{array}{l}\text { Cerebellar } \\
\text { siderosis }\end{array}$ & $\begin{array}{l}\text { Recent } \\
\text { haemorrhage }\end{array}$ & $\begin{array}{l}\text { Type of } \\
\text { recent } \\
\text { haemorrhage }\end{array}$ \\
\hline Acute death & 4 & $22(4)$ & 0 & 0 & 0 & $1 \dagger$ & 0 & 4 & $\mathrm{SD} / \mathrm{SA}+\mathrm{SD} / \mathrm{SA}$ \\
\hline \multirow{2}{*}{$\begin{array}{l}\text { Ex-professional } \\
\text { Ex-amateur or } \\
\text { doubtful status }\end{array}$} & 10 & $66(8)$ & 10 & 1 & 5 & 5 & 4 & 1 & ANG \\
\hline & 8 & $67(12)$ & 5 & 4 & 2 & 2 & 2 & 2 & IC \\
\hline
\end{tabular}

*Data in Corsellis et al (1973).

†In coma for 1 year after boxing bout.

SD, Subdural haemorrhage; SA, Subarachnoid haemorrhage; ANG, Angiomatous haemorrhage; IC, Intracerebral haemorrhage.

haemorrhage or a combination of these complications. The other five boxers (four amateurs and one professional) had lived for many years after the end of their boxing careers. The brains of three of the latter five cases showed the typical stigmata of dementia pugilistica (table).

The brains from 94 "control" patients were also studied. Their ages ranged from 54-95 years; most had died from cardiovascular disease.

Sections of paraffin blocks were stained with $H$ \& $E$,
Mallory's phosphotungstic acid haematoxylin, HeidenhainWoelcke's stain for myelin and Perls' ferrocyanide method for iron.

\section{Results and comment}

Histological sections from all 22 boxers' brains were re-examined. Three of the four cases who had died soon after a boxing bout showed evidence of recent

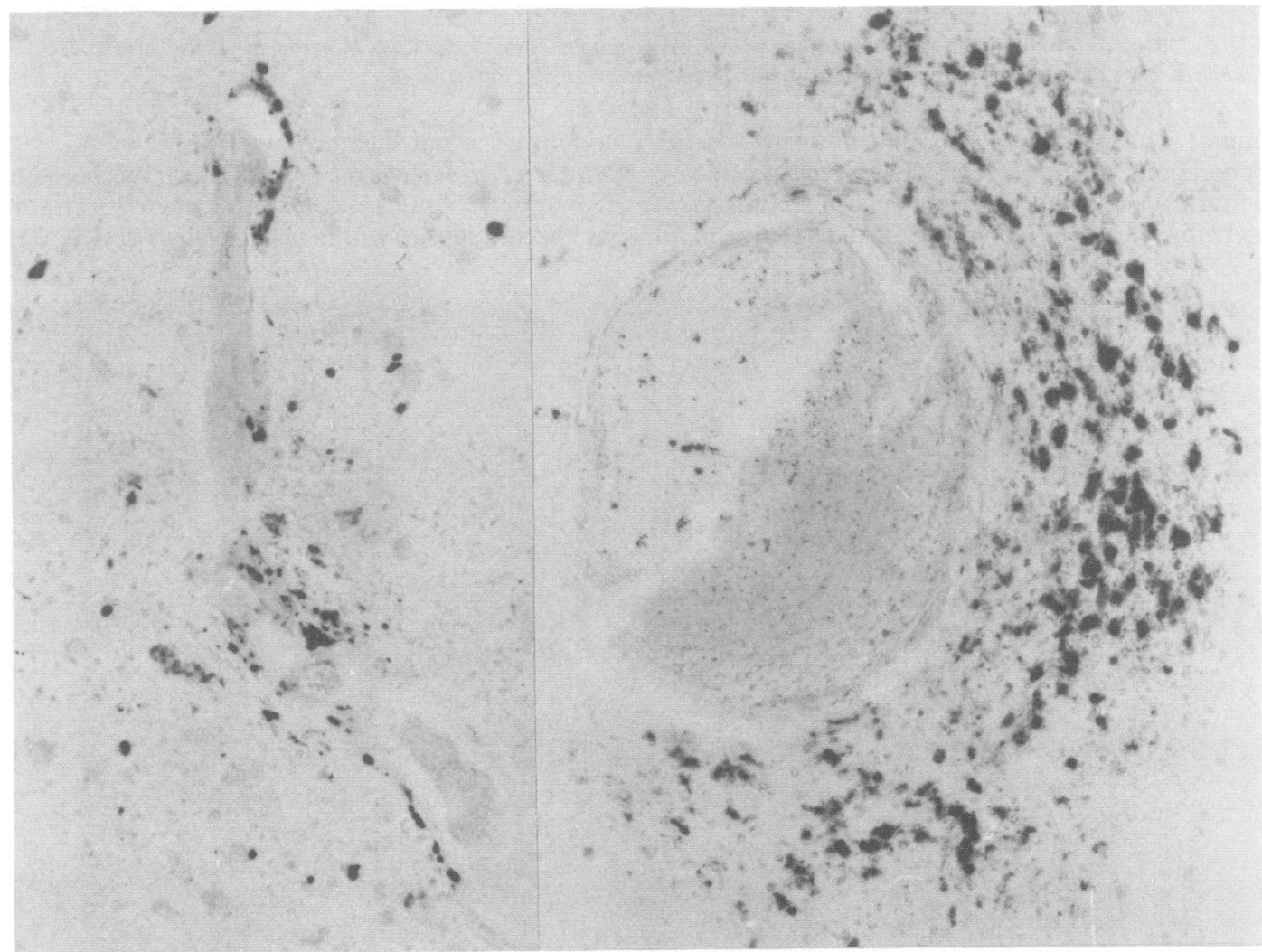

Fig 1 Left perivascular accumulation of haemosiderin (iron) in the cerebellum of an ex-professional boxer aged 53 yr. Right massive haemosiderin deposition around a small cortical artery in an ex-professional boxer aged 63 yr. Both Perls', ferrocyanide $\times 100$. 


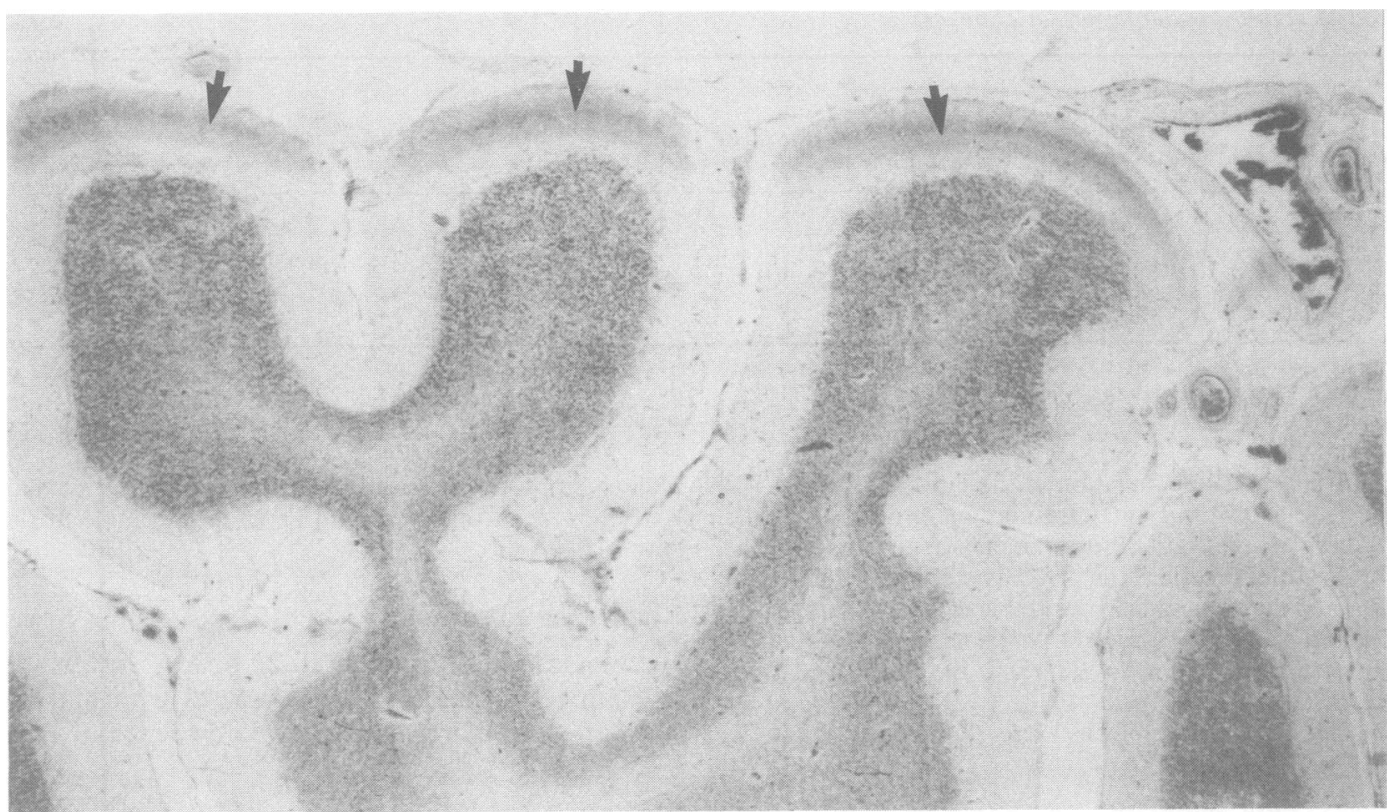

Fig 2 Siderosis of the subpial region (arrows) of the cerebellum in an ex-professional boxer aged $67 \mathrm{yr}$. This subject had probably suffered from past subdural or subarachnoid haemorrhage. Perls', $\times 40$.

subdural haemorrhage combined with either and intracerebral haemorrhage.

subarachnoid or intracerebral haemorrhage (table); Intracerebral haemorrhage Seven of the remaining the fourth boxer who had remained in a coma for a year before death had evidence of old subarachnoid 18 ex-boxers' brains showed intracerebral iron-staining (haemosiderin) within macrophages or neurologia

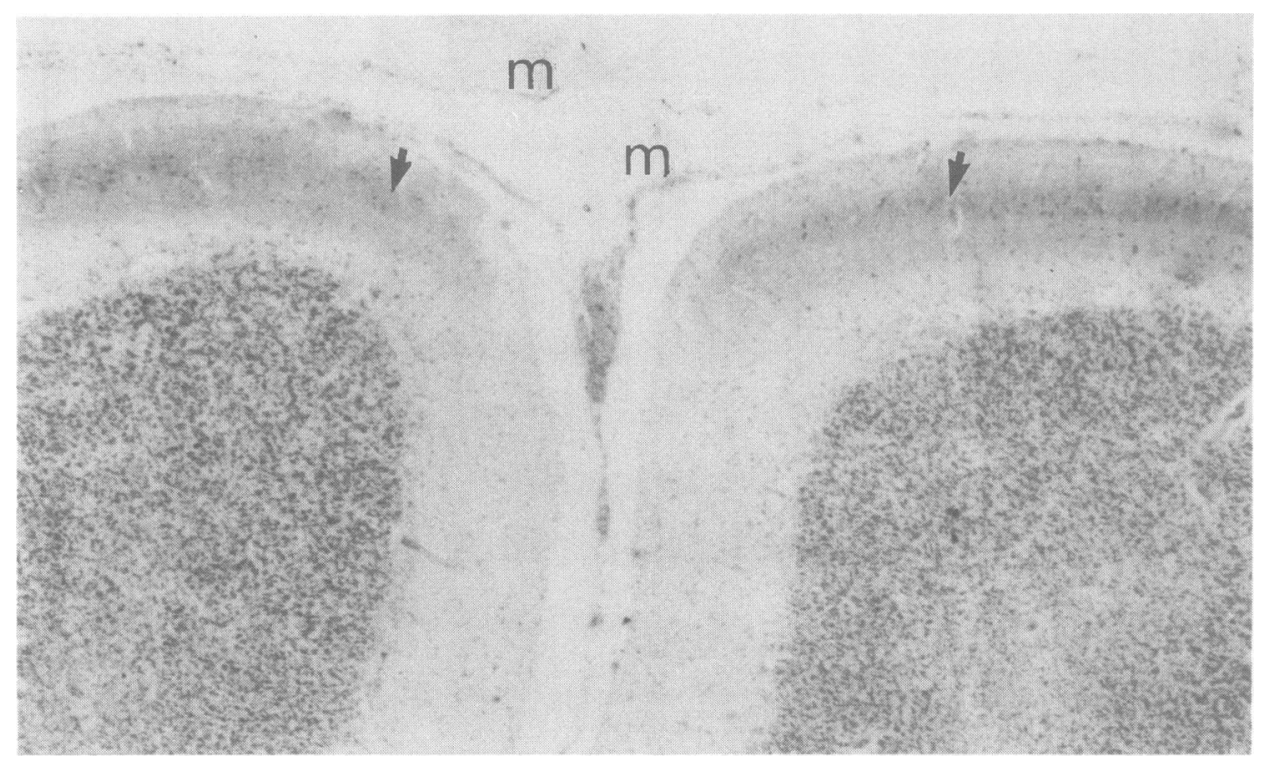

Fig 3 Same case as fig 2. Note subpial siderosis of the cerebellum (arrows) and iron deposition in the meningeal membranes $(m, m)$. Perls', $\times 70$. 
or free-lying around cerebral or cerebellar blood vessels (fig 1 , table). Although perivascular iron and calcium deposition is not uncommonly found in the brains of normal old people, ${ }^{9}$ the affected boxers were all under 65 years of age and, in general, younger than those boxers who showed no such change $(\mathrm{N}=18$, df $\left.=1, \chi^{2}=6.491, p<0.005\right)$. The perivascular iron would therefore seem unlikely to be the result of normal ageing. Furthermore, the cerebral vessels of the boxers showed neither hypertensive change nor other vascular pathology..$^{10}$

In total, nearly $39 \%$ of the ex-boxers showed evidence of past intracerebral haemorrhage; this figure is nearly four times the $11 \%$ recorded in the 94 control brains (table) and also in a separate study of 70 control patients."

Meningeal haemorrhage Histological evidence of iron-staining was also present in the meninges, the subpial region and/or around the cranial nerves of seven of the 18 ex-boxers presumably as a result of past non-fatal bleeding. Indeed, two of these cases showed naked-eye evidence of previous haemorrhage in the form of a localised brownish staining of the leptomeninges. Of the seven cases with evidence of past meningeal haemorrhage, five showed a patchy or continuous band of iron staining in the subpial regions of the cerebellum or the pons (figs 2 and 3), which resembled that seen in patients with subpial haemosiderosis. ${ }^{12-17}$ Koeppen and Dentinger ${ }^{17}$ observed that minor degrees of subpial haemosiderosis are not infrequent, but do not give rise to cerebellar ataxia, eight nerve deafness and myelopathy, which are the clinical features of more severe cases.

The subpial haemosiderosis seen in the boxers was sometimes found within glial cells but often was distributed more diffusely over glial fibres in the manner described by Lillie, ${ }^{18}$ Hughes and Oppenheimer ${ }^{15}$ and Pearse. ${ }^{19}$ Pearse attributed the diffuse staining to the binding of iron by acid mucopolysaccarides (glycosaminoglycans), similar to that seen with Hale's colloidal iron test.

In all, 11 of the 22 brains showed evidence of recent or old meningeal haemorrhage; four of which proved to be fatal.

Cerebellar siderosis Six ex-boxers showed evidence of minor cerebellar siderosis, namely iron deposition in the white matter of the cerebellar folia and three of the six had focal iron deposition over Bergmann glia and Purkinje cells. One of the patients also showed ferrugination of the Purkinje cells. However, these cerebellar changes were but a minor manifestation of those seen in the fully developed superficial siderosis of the CNS. They were unlikely to be the cause of the cerebellar signs of dementia pugilistica, ${ }^{1}$ as they were noted in only three of the 13 original cases that we were able to study.
Conclusions No less than 17 of the 22 ex-boxers showed evidence of past cerebral, cerebellar or meningeal haemorrhage which had occurred sometime during the boxer's life, although the extent of past haemorrhage was less evident in the amateurs than in the ex-professional boxers (table, $\mathrm{N}=22, \mathrm{df}=1, \chi^{2}$ $=5.297, \mathrm{p}<0.02$ ).

However, even in the ex-professional boxers the degree of cerebral damage, as measured by the amount of free-lying haemosiderin, was relatively minor and almost certainly could not have accounted for the extensive neuropathology that characterises the "punch-drunk" state. In fact the damage appeared to be additional to the cerebral pathology normally associated with dementia pugilistica. Nevertheless, it is self-evident that in any one of these 17 cases, the haemorrhages could have been fatal. Indeed no less than four were so.

\section{References}

1 Corsellis JAN, Bruton CJ, Freeman-Browne D. The aftermath of boxing. Psychol Med 1973;3:270-303.

2 Corsellis JAN. Post traumatic dementia. In Alzheimer's disease: Senile dementia and related disorders. Katzman R, Terry RD, Blick KL, eds. Aging (Vol 7). New York: Raven Press, 1978:125-33.

3 Martland HS. "Punch-Drunk". JAMA 1928;91:1103-7.

4 Cassasa CB. Multiple traumatic cerebral haemorrhages. Proc NY Path Soc 1924;24:101. (Cited by Martland, 1928.)

5 Unterharnscheidt F. Injuries due to boxing and other sports. In: Vinken JJ, Bruyn GW, eds. in collaboration with Brackman R. Handbook of Clinical Neurology 1975;23:527-93. Amsterdam: North Holland Publ Co.

6 Adams JH. Head injury. In: Hume Adams J, Corsellis JAN, Duchen LW, eds. Greenfield's Neuropathology 4th ed, chap 3. London: Arnold, 1984:85-124.

7 Ommaya AK, Gennarelli TD. Cerebral concussion and traumatic unconsciousness: correlation of experimental and clinical observations on blunt head injuries. Brain 1974;97:633-54.

8 Adams JH, Graham DI, Gennarelli TA. Neuropathology of acceleration-induced head injury in the subhuman primate. In: Grossman RG, Gildenberg PL, eds. Head Injury: Basic and Clinical Aspects. New York: Raven Press, 1982:141-50.

9 Wertham F, Wertham F. The Brain as an Organ: Its Postmortem Study and Interpretation. New York: Macmillan, 1934:285.

10 Cervos-Navarro J, Roggendorf W. Pathological changes in the vessel wall of intracerebral veins; an ultrastructural study. In: Auer LM, Heppner F, eds. The Cerebral Veins, An Experimental and Clinical Update. Wien: Springer-Verlag, 1983:47-55.

11 Adams CWM. Perivascular iron deposition and other vascular damage in multiple sclerosis. $J$ Neurol Neurosurg Psychiatry 1988;51:260-5.

12 McGee DA, Van Patter HJ, Morotta J. Olszewski J. 
Subpial cerebral siderosis. Neurology 1962;12:108-13.

13 Tomlinson BE, Walton JN. Superficial haemosiderosis of the central nervous system. J Neurol Neurosurg Psychiatry 1964;27:332-9.

14 Braham J, Wolman M. Subpial siderosis of the central nervous system. Acta Neuropathol 1965;74:559-62.

15 Hughes JT, Oppenheimer DR. Superficial siderosis of the central nervous system. Acta Neuropathol 1969;13: 56-74.

16 Koeppen AH, Barron KD. Superficial siderosis of the central nervous system. J Neuropathol Exp Neurol 1971;30:448-69.

17 Koeppen AHW, Dentinger MP. Brain hemosiderin and superficial siderosis of the central nervous system. $J$ Neuropathol Exp Neurol 1988;47:249-70.

18 Lillie RD. Histopathological Technic and Practical Histochemistry. 3rd edn. New York: Blakiston, 1965: $388-428$

19 Pearse AGE. Histochemistry. 3rd edn. London: Churchill-Livingstone, 1972:1069, 1402.

\section{Encephalitis lethargica}

"Marie and Levy (Revue Neurologique, 1920) have drawn attention to a group of cases in which the musculature of the face, tongue, jaws, and pharynx is especially affected by the occurrence of either involuntary movements or hypertonus. In these patients there may be clonic contractions of muscles or parts of muscles, or rhythmic tremors of antagonistic groups, which in the case of the jaw muscles may result in chattering of the teeth. In certain cases trismus has been observed."

Symonds, CP. Encephalitis lethargica. Q J Med 1921;55:283-308.

RT ROSS

\section{Pink disease}

"There is a clinical entity ... common in the second year of life which presents the following characteristics:

(a) Erythroedema: coldness, redness, swelling of the hands, feet, cheeks, and nose with desquamation.

(b) Perspiration of the whole body ... with a mouse-like odour and falling out of the hair.

(c) Extreme mental misery, irritability, insomnia, and obstinate anorexia.

(d) Muscular hypotonia, loss or diminution of tendon reflexes, and relative or absolute anasthesia."

Donald Paterson and J Godwin Greenfield. Erythroedema polyneuritis (the so-called “Pink Disease”). QJ Med 1923;65:6-18.

RT ROSS

\section{Encephalitis in children}

"From a study of $\mathbf{4 0}$ cases of encephalitis lethargica in childhood we have come to regard disturbances of sleep sequence, psychical changes, and the development of troublesome habits as the most frequent sequelae. Chorea, ... developed during the acute stages of the disease ... tended to recur in combination with various sequelae for long periods after apparent recovery. Paralysis of cranial nerves was not uncommon during the acute illness, but never recurred ... . Parkinsonian tremor developed in only one case (from a study of 40 cases), but a mask-like expression, . . accompanied by slow scanning speech without other symptoms of paralysis agitans was of frequent occurrence."

Grace $\mathrm{H}$ Anderson. The sequelae of epidemic encephalitis in childhood with notes on the prognosis as regards complete recovery. $Q J$ Med 1923;63:173-92.

RT ROSS

\section{Periosteal neurofibromatosis}

“The famous 'elephant man' (Merrick), whom I once saw, and who died at the London Hospital at the age of 27 years (on April 11, 1890) had many deformities of the nature of pachydermatoceles as well as many boney thickenings and outgrowths. There was no post-mortem examination, but a regular periosteal neurofibromatosis may well have played a part in his osseous deformities.

Periosteal neurofibromatosis . . . hardly recognized as such until Brooks and Lehman drew attention to the subject in 1924 ... is probably present in all the cases roughly grouped together as neurofibromatosis elephantiasis of limbs, especially those which show definite excess in bone length. Such cases are apparently nearly always unilateral."

Parkes Weber, F. Periosteal neurofibromatosis, with a short consideration of the whole subject of neurofibromatosis. $Q J M e d$ 1929;23:151-66. 